\title{
Primary tumor location affects recurrence-free survival for patients with colorectal liver metastases after hepatectomy: A propensity score matching analysis
}

\section{Yuanping Zhang \\ Sun Yat-sen University Cancer Center}

Yongjin Wang

Sun Yat-sen University Cancer Center

Yichuan Yuan

Sun Yat-sen University Cancer Center

Jiliang Qiu

Sun Yat-sen University Cancer Center

Yuxiong Qiu

Sun Yat-sen University Cancer Center

Wei He

Sun Yat-sen University Cancer Center

Yun Zheng

Sun Yat-sen University Cancer Center

Zhiqiang Wang

Sun Yat-sen University Cancer Center

Yangkui Gu

Sun Yat-sen University Cancer Center

Zhenhai Lu

Sun Yat-sen University Cancer Center

Gong Chen

Sun Yat-sen University Cancer Center

Peirong Ding

Sun Yat-sen University Cancer Center

Xiaojun Wu

Sun Yat-sen University Cancer Center

Zhizhong Pan

Sun Yat-sen University Cancer Center

\section{Desen Wan}

Sun Yat-sen University Cancer Center

Yuhong Li

Sun Yat-sen University Cancer Center

\section{Ruihua Xu}

Sun Yat-sen University Cancer Center

Yunfei Yuan

Sun Yat-sen University Cancer Center 
Binkui Li ( $\square$ libk@sysucc.org.cn )

Sun Yat-sen University Cancer Center

\section{Research}

Keywords: Colorectal cancer, Liver metastases, Location, Prognosis

Posted Date: May 14th, 2020

DOI: https://doi.org/10.21203/rs.3.rs-16361/v2

License: (c) (i) This work is licensed under a Creative Commons Attribution 4.0 International License. Read Full License

Version of Record: A version of this preprint was published at World Journal of Surgical Oncology on May 18 th, 2020. See the published version at https://doi.org/10.1186/s12957-020-01875-y. 


\section{Abstract}

Background: Whether primary tumor location of colorectal cancer (CRC) affects survival of patients after resection of liver metastases remains controversial. This study was conducted to investigate the differences in clinicopathological characteristics and prognosis between right-sided CRC and left-sided CRC patients with liver metastases after hepatectomy.

Methods: From 2002 to 2018, 611 patients with colorectal liver metastases (CRLM) who underwent hepatectomy at our center were reviewed. Primary tumors located from cecum to transverse colon were defined as right-sided group (n = 141); tumors located from splenic flexure to rectum were defined as left-sided group $(n=470)$. Patients were compared between two groups before and after a 1:1 propensity score matching (PSM) analysis.

Results: Before PSM, median survival time and 5-year overall survival (OS) rate in right-sided group were 77 months and $56.3 \%$, and those in left-sided group were 64 months and $51.1 \%$, respectively. After PSM, median survival time and 5 -year OS rate in right-sided group were 77 months and 55.9\%, and those in left-sided group were 58.8 months and $47.3 \%$, respectively. The OS rates did not differ between two groups before and after PSM $(P=0.575 ; P=0.453)$. However, significant different recurrence-free survival (RFS) rate was found before and after PSM between right-sided and left-sided group $(P=0.028, P=0.003)$.

Conclusions: Compared to patients with left-sided primary tumors, patients with right-sided primary tumors had a worse RFS but similar OS. Careful preoperative evaluation, intensive preoperative chemotherapy and frequent followup to detect early recurrence might be justified for CRLM patients with right-sided primary tumors.

\section{Background}

Colorectal cancer (CRC) is the third most commonly diagnosed cancer in the world[1]. In Asia, its incidence and mortality has been also on the rise over recent decades[2]. Colorectal liver metastases (CRLM) present in 20-25\% of patients at the time of diagnosis and in approximately $60 \%$ of patients during the course of the disease[3]. Despite improvements in the comprehensive management of patients with CRLM in recent years, liver resection remains the most effective treatment with the potential for long-term survival and cure for CRLM patients[4].

In CRLM patients undergoing hepatic resection, many factors such as tumor size of liver metastases, tumor number and serum carcinoembryonic antigen (CEA) level are associated with outcomes[5]. Primary tumor factors including lymph node status, pathology grade and genetic status may also influence the survival [6, 7]. Besides survival, genetic status of primary tumor were also found to predict resection margin and pathologic response in CRLM patients treated with neoadjuvant chemotherapy[8, 9].

Primary tumor location has been reported as a potential prognostic factor in patients with CRC. There is growing evidence that patients with right-sided CRC tend to present with higher TNM stage, larger tumor size and worse outcomes than those with left-sided CRC[10,11]. Genetic differences may account for distinct carcinogenesis and biological behavior and lead to worse prognosis in right-sided CRC patients[12, 13]. However, the value of primary tumor location in determining prognosis of patients with CRLM remains controversial, due to the contradicting results in existing studies[14, 15].

In this study, we aimed to explore the impact of primary tumor location of CRC on clinical characteristics and survival for CRLM patients undergoing hepatectomy. Propensity score matching (PSM) was used to strengthen causal arguments in observational study by reducing selection bias. 


\section{Methods}

\section{Patients and Study design}

All pathologically confirmed CRLM patients undergoing hepatectomy at Sun Yat-sen University Cancer Center between July 2002 and March 2018 were included. Demographic and clinicopathologic variables were collected with review of the medical record. To avoid the impact of different pathological type for prognosis, only pathological type of adenocarcinoma was included. All patients received primary tumor resection prior to or combined with hepatectomy. Exclusion criteria consisted of: Child-Pugh score of C, Eastern Cooperative Oncology Group-performance status (ECOG-PS) >2, had double primary malignancies, lost in follow-up. According to the anatomical location, primary tumors located from cecum to transverse colon were defined as right-sided group and tumors located from splenic flexure to rectum were defined as left-sided group. Differences in clinicopathological characteristics and prognosis between two groups (left-sided group vs. right-sided group) were compared to determine whether the primary tumor location of CRC affecting survival of patients after resection of liver metastases. The primary endpoints of this study were overall survival (OS) and recurrence-free survival (RFS). The OS was defined as the time interval from liver resection to death from any cause or the last follow-up date. RFS was defined as the time interval from liver resection to disease recurrence, death from disease, or the last follow-up date.

Preoperative blood tests which included tumor markers were carried out within 2 weeks before resection of CRLM. Image to evaluate the resectabililty of liver metastases included magnetic resonance imaging (MRI) or computed tomography (CT). Intraoperative ultrasonography (US) was performed as conventional procedure to conduct radical resection of all tumors if possible. Definition of R0 resection is resection of liver lesions with clear histological margins, and non R0 (R1/R2) resection is resection with histological positive margins or residual lesions in intra or extrahepatic. Liver metastases diagnosed before, during or within 3 months after colorectal resection is defined as synchronous metastases.

The clinical risk score (CRS) used in the study was an established risk score冈the 'Fong' score, which is consisting of five clinical factors, including primary lymph node metastasis, synchronous metastases, multiple liver tumors, tumor size over $5 \mathrm{~cm}$, and carcinoembryonic antigen (CEA) over $200 \mathrm{ng} / \mathrm{ml}[5]$. Each of 5 clinical factors is assigned 1 point. Patients with a CRS of 0-2 were classified into the low-risk subgroup, while patients with a CRS of 3-5 were classified into the high-risk subgroup.

\section{Follow-ups}

All patients were followed up monthly in the first 3 months, every 3 months in the first two years and every 3 to 6 months thereafter. Physical examination, blood tests, abdominal and pelvic US or CT/MRI were used for the surveillance of recurrence as appropriate.

\section{Statistical analysis}

In all patients, propensity score matching (PSM) was performed to reduce selection bias. Propensity scores were estimated using a logistic regression model based on age, gender, primary tumor lymph nodes status, time of liver metastases, preoperative CEA level, preoperative chemotherapy, number of liver metastases and size of largest liver lesions. A 1:1 nearest neighbor matching without replacement was performed using a 0.2 caliper width. The potential residual imbalance after matching was tested through univariate (standardized mean difference [SMD] cut-off: 0.25) and multivariate tests (Hansen-Bowers test; lacus-King-Porro test). The resulting score-matched pairs were used in subsequent analyses as indicated. Consecutive data were presented as mean (square deviation, SD). Independent- 
sample T-test, Chi-square test or Fisher's exact test were used for analyzing the differences in clinicopathological characteristics between two groups as appropriate. The OS and RFS curves were constructed by Kaplan-Meier method and compared with the log-rank test. Cox proportional hazard regression model was performed to identify the hazard ratio (HR) of prognostic factors. A $P$ value less than 0.05 was regarded as statistically significant. All $P$ value of statistical tests in the present study were two-sided. All statistical calculations were performed with IBM SPSS Statistics 25.0 software package (SPSS Inc., Chicago, IL).

\section{Results}

\section{Clinicopathological characteristics}

Of the 611 patients, 141 (23.1\%) had primary tumors located in right-sided CRC, and 470 (76.9\%) had primary tumors located in left-sided CRC. Clinicopathological characteristics of two groups were presented in Table 1. Compared to left-sided group, right-sided group tended to have larger tumor size in CRC (4.2 vs. $3.6 \mathrm{~cm}, P=0.011)$ and less people underwent preoperative chemotherapy before hepatectomy (48.2 vs. $61.1 \%, P=0.008$ ). Other baseline parameters such as largest size of liver tumors, number and distribution of liver metastases were comparable between two groups.

After PSM, 127 matched pairs were generated from right-sided and left-sided groups. The standardized mean differences of included PSM factors were decreased (Table 1). Also, Hansen-Bowers test for global imbalance was not significant $(P=0.996)$ and the lacus-King-Porro test showed that L1 was reduced in the matched sample, indicating the improvement of the overall balance (L1: before matching 0.929; after 0.899). The reduction of imbalance is pictured by histograms with overlaid kernel density estimates for SMD (Supplementary Figure 1).

\section{Survival analysis}

The average follow-up interval for all the included patients was 36.9 months (range: 2.2-151.5 months). The median OS for right-sided group and left-sided group were 77 months and 64 months respectively. The 1-, 3- and 5-year OS rates after CRLM resection in right-sided group were $91.0 \%, 75.0 \%$ and $56.3 \%$, respectively, and $94.9 \%, 84.8 \%$, and $51.1 \%$, respectively, in left-sided group $(P=0.575$; Figure $1 \mathrm{a})$. The 1-, 3- and 5-year RFS rates after R0 resection of liver metastases in right-sided group were $27.8 \%, 10.1 \%$, and $5.1 \%$, respectively, and $40.9 \%, 22.6 \%$, and $8.8 \%$, respectively, in left-sided group. Left-sided group have a significant better RFS rate than right-sided group ( $P=0.028 ;$ Figure $1 \mathrm{~b})$.

After PSM, the median OS time for patients in right-sided group was 77 months and was 58 months in left-sided group. Cumulative 1-, 3- and 5-year OS rates were $89.2 \%, 64.2 \%$ and $55.9 \%$, respectively, in right-sided group, compared to $95.9 \%, 75.7 \%$ and $47.3 \%$, respectively, in left-sided group ( $P=0.453$; Figure $1 \mathrm{c})$. The median RFS for patients in right-sided group was 5.8 months and was 10.9 months for patients in left-sided group. Cumulative 1-and 3-year RFS rates were $25.9 \%$ and $10.1 \%$, respectively, in the patients from right-sided group, compared to $48.8 \%$ and $17.2 \%$, respectively, in patients from left-sided group $(P=0.003$; Figure $1 \mathrm{~d})$.

\section{Prognosis stratified by CRS score and tumor number}

We further explored the prognostic role of CRC location according to CRS scores and liver lesions. Similar OS were found in CRLM patients stratified by CRC location with different CRS scores. Significant worse RFS were found in right-sided group before and after PSM among patients with low CRS scores $(P=0.037, P=0.011$; Figure 2). However, RFS were comparable before and after PSM between right-sided and left-sided group with high CRS scores $(P=0.284$, $P=0.117$; Figure 3). Among patients with single liver lesion, OS and RFS were comparable before and after PSM 
between right-sided and left-sided group $(P=0.322, P=0.338 ; P=0.191, P=0.118$; Supplementary Figure 2$)$. Among patients with multiple liver metastases, significant worse RFS were also found in right-sided group before and after $\operatorname{PSM}(P=0.022, P=0.012$; Supplementary Figure $3 b, 3 d)$.

\section{Prognostic Factors for patients after resection of liver metastases}

Next, we performed univariate and multivariate analysis to identify prognostic factors in our patients. Factors including lymph node metastases (HR 1.600, 95\% confidence interval [Cl] 1.155-2.216, $P=0.005$ ), liver lesions $>5 \mathrm{~cm}$ (HR 1.923, 95\% Cl 1.298-2.849, $P=0.001$ ) and non-R0 resection (HR 1.998, 95\% Cl 1.424-2.804, $P<0.001$ ) were found to affect OS (Table 2). For RFS, significant factors in multivariate analysis were tumor location $(\mathrm{HR} 0.659,95 \% \mathrm{Cl}$ 0.478-0.910, $P=0.011$ ), lymph node metastases (HR 1.533, 95\% Cl 1.159-2.029, $P=0.003$ ) and resection combined with ablation (HR 1.793, 95\% Cl 1.253-2.566, $P=0.001$ ) (Table 2).

\section{Treatment of recurrence}

Of the 611 patients, 240 (39.3\%) patients had recurrence after liver metastases resection. There were 99 (39.0\%) patients with relapsed after PSM. Treatment modality of recurrence in two groups were presented in Table 3 . Before PSM, 41 (75.9\%) and 119 (64.0\%) patients underwent resection/ ablation/ chemotherapy alone and 13 (24.1\%) and $67(36.0 \%)$ patients underwent combined therapy in right-sided and right-sided group, respectively. Treatment modality of recurrence in two groups was comparable between two groups before and after PSM.

\section{Discussion}

Many clinicopathological factors and molecular features affect survival of CRC patients[16]. Among them, primary tumor location of CRC is a notable factor which can affect outcomes of patients[17]. So far, many evidence have revealed that right-sided CRC patients have poorer prognosis than left-sided CRC patients[18]. Differences in RAS status, microsatellite instability (MSI) and CpG island methylator (CIMP) phenotype may account for diverse clinicopathological characteristics and outcomes between right-sided and left-sided CRC patients[19].

Recently, data from two pooled studies have shown that OS, progress free survival and objective response rate were much worse among unresectable CRLM patients with right-sided tumor than those with left-sided tumor[20, 21]. However, whether primary tumor location of CRC affects prognosis of CRLM patients after hepatectomy remains debatable. One study found CRLM patients with left-sided CRC have worse disease free survival but better OS after liver resection, as authors suggested that tumors of patients with right-sided CRC relapsed less frequently than leftsided patients, but they had more aggressive disease once they recurred[22]. A meta-analysis concluded that CRLM patients with right-sided CRC had worse OS than those with left-sided CRC[15]. It should be noted that this analysis included nine non-Asian countries and only three studies from Asian countries. Some other studies showed that primary tumor location did not influence prognosis of CRLM patients after hepatectomy[23-25]. In CRLM patients after microwave ablation, comparable outcomes were also observed between right-sided group and left-sided group[26, 27]. As such, whether primary tumor location of CRC affects prognosis of CRLM patients after hepatectomy remains debatable.

In our study, most baseline parameters such as largest size of liver tumors, number and distribution of liver metastases were comparable between two groups. However, selection bias might not have been completely avoided due to the retrospective nature of this study. By statistical adjustment, PSM is able to take full advantage of a large amount of data despite an observational design[28]. Application of PSM may have helped balance the underlying biases that were not analyzed in the study. 
Compared with previous similar studies, our study has the following differences and new findings. First, the sample size of our study was larger and PSM analysis was implemented to reduce the impact of selection bias on results. Second, as far as we know, unlike previous reports, our results show for the first time that the RFS in CRLM patients from the right-sided was poorer than those from the left-sided, but with no difference in OS. Third, we also conducted a further subgroup analysis to investigate the prognostic effects of the primary tumor location on patients with different CRS and tumor numbers. We found that with low CRS or multiple tumors, patients with CRLM from the rightsided had a higher recurrence rate than those from the left-sided. Overall, these novel findings suggest that patients with CRLM from the right-sided may need to receive intensive preoperative chemotherapy to eliminate micrometastatic disease and, more importantly, to further identify aggressive disease and select good candidates for surgery. Additionally, the benefit of surgery and high risk of recurrence should be carefully taken into consideration. On the other hand, less invasive non-surgical strategies for small liver lesions such as radiofrequency ablation or stereotactic body radiotherapy (SBRT) might be an effective alternative to resection as the first-line treatment. It should be noted that subsequent treatments are crucial for prolonging survival of patients after recurrence. Thus, more frequent follow-up after surgery to detect early recurrence may help improve the prognosis of these patients.

Compared to the CRLM from the left-sided, the more aggressive tumor behaviour of the CRLM from the right-sided may contribute to its worse RFS. Early studies have shown that tumors in the right colon were larger, more often poorly differentiated and more often had a peritumoral lymphocytic infiltrate than tumors in the left colon and rectum[10]. Besides, right-sided CRC was more characterized by high MSI (MSI-H) and more BRAF mutations[29]. Many studies demonstrated that right-sided CRC patients presented with a significantly worse survival than those with left-sided $\mathrm{CRC}[11,30]$. As there is a high concordance of molecular characteristics between primary CRC and their corresponding liver metastases, even after R0 resection, aggressive biological behaviour may lead to shorter time to recurrence in CRLM patients from the right-sided[31]. The disparity between the results of RFS and OS may due to benefit of subsequent therapies after recurrence. Tumors may recur more frequently in CRLM patients with right-sided CRC, but efficient and multi-discipline therapies to treat recurrence lesions may result in comparable prognosis.

The inconsistent effects of primary tumor location in CRC and CRLM patients may be partially explained by following reasons. Firstly, there were studies reported that prognosis were much worse among unresectable CRLM patients from right-sided CRC than those from left-sided $\mathrm{CRC}[20,21]$. Therefore, there might be more patients with unresectable CRLM and/or extrahepatic disease which was unable to convert to resectable disease from right-sided CRC than from left-sided CRC. These unresectable patients accounted for the majority of population and had a greater impact on the overall prognosis. Thus, as indicated in our study and other studies, although the results showed that the OS were comparable in patients with resectable CRLM from right-sided and left-sided CRC, these are not contradictory to previous reports that right-sided CRC patients had worse OS than left-sided CRC patients. Secondly, since resection of liver metastases is the potentially curative approach for CRLM patients, the benefits of hepatectomy may neutralize the prognostic effect of primary tumor location for CRLM patients[24, 25]. Thirdly, the prognostic value of primary tumor location may depend on tumor stages. There were evidences that survival was not affected by tumor location in early stage CRC patient while it was influenced in patients with advanced unresectable CRLM[18, 32, 33]. Moreover, difference in ethnicity may also contribute to the discrepancy in result. Therefore, the prognostic value of tumor location needs further prospective investigation.

It is important to note the limitations in our study. Although PSM was used to reduce selection bias caused by retrospective design, our study only included patients in a single institution. Furthermore, genetic information such as RAS type and BRAF type were not available in most of our patients. We were unable to assess the prognostic impact of genetic status in two groups. Hence, future studies which include multicenter, large scale of patients with genetic data are needed to confirm our conclusion. 


\section{Conclusion}

Compared to patients with left-sided primary tumors, patients with right-sided primary tumors had a worse RFS but similar OS. Careful preoperative evaluation, intensive preoperative chemotherapy and frequent follow-up to detect early recurrence might be justified for CRLM patients with right-sided primary tumors.

\section{Declarations}

\section{Acknowledgments}

We appreciated all authors for their efforts on the manuscript.

\section{Authors' contributions}

BKL and YYF contributed to the research design; YPZ, YJW, YCY, JLQ, YXQ, WH, YZ, ZQW, ZZP, DSW, YHL, ZHL, GC, PRD, XJW and YKG contributed to the data collection, data analysis, and manuscript writing. YPZ, YJW, YCY, YZ and JLQ contributed to the data collection and manuscript writing. All authors contributed to the writing review and editing. All authors read and approved the final manuscript.

\section{Funding}

This work was supported by grants from the National Natural Science Foundation of China (No. 81772625, and 81772598), the Natural Science Foundation of Guangdong Province (2017A030311006), the Fundamental Research Funds for the Central Universities of China (18ykpy36) and the Guangdong Key Laboratory of Liver Disease Research (GS2017101001).

\section{Availability of data and materials}

The datasets generated during and/or analyzed during the current study are available from the corresponding author on reasonable request.

\section{Ethics approval and consent to participate}

Ethical approval was waived by the Sun Yat-sen University Cancer Centre in view of the retrospective nature of the study and all the procedures being performed were part of the routine care. This study was performed in accordance with the Helsinki Declaration of 1975.

\section{Consent for publication}

Not applicable.

\section{Competing interests}

The authors declare that they have no competing interests.

\section{Abbreviations}

CRC: colorectal cancer; CRLM: colorectal liver metastases; PSM: propensity score analysis; OS: overall survival; RFS: recurrence-free survival; CRS: clinical risk score; CEA: carcinoembryonic antigen; ECOG-PS: Eastern Cooperative Oncology Group-performance status; MRI: magnetic resonance imaging; CT: computed tomography; US: 
ultrasonography; SMD: standardized mean differences; HR: hazard ratio; Cl: confidence interval; MSI: microsatellite instability; CIMP: CpG island methylator; SBRT: stereotactic body radiotherapy

\section{References}

1. Siegel RL, Miller KD, Fedewa SA, Ahnen DJ, Meester RGS, Barzi A, Jemal A: Colorectal cancer statistics, 2017.CA Cancer J Clin 2017, 67:177-193.

2. Torre LA, Siegel RL, Ward EM, Jemal A: Global Cancer Incidence and Mortality Rates and Trends-An Update.Cancer Epidemiol Biomarkers Prev 2016, 25:16-27.

3. Kemeny $\mathrm{N}$ : The management of resectable and unresectable liver metastases from colorectal cancer.Curr Opin Oncol 2010, 22:364-373.

4. Vellinga TT, Kranenburg O, Frenkel N, Ubink I, Marvin D, Govaert K, van Schelven S, Hagendoorn J, Borel Rinkes IH: Lymphangiogenic Gene Expression Is Associated With Lymph Node Recurrence and Poor Prognosis After Partial Hepatectomy for Colorectal Liver Metastasis.Ann Surg 2017, 266:765-771.

5. Yuman Fong, Joseph Fortner, Ruth L. Sun B, Murray F. Brennan, Blumgart LH: Clinical Score for Predicting Recurrence After Hepatic Resection for Metastatic Colorectal Cancer: Analysis of 1001 Consecutive Cases. Ann Surg 1999, 230:309-321.

6. Kazunari Sasaki, Georgios A. Margonis, Ana Wilson D, Yuhree Kim,, Stefan Buettner, B.Sc NA, Faiz Gani, Neda Amini, Gaya Spolverato, Pawlik TM: Prognostic Implication of KRAS Status after Hepatectomy for Colorectal Liver Metastases Varies According to Primary Colorectal Tumor Location.Ann Surg Oncol 2016, 23:3736-3743.

7. Pai RK, Jayachandran P, Koong AC, Chang DT, Kwok S, Ma L, Arber DA, Balise RR, Tubbs RR, Shadrach B, Pai RK: BRAF-mutated, microsatellite-stable adenocarcinoma of the proximal colon: an aggressive adenocarcinoma with poor survival, mucinous differentiation, and adverse morphologic features.Am J Surg Pathol 2012, 36:744-752.

8. Brudvik KW, Mise Y, Chung MH, Chun YS, Kopetz SE, Passot G, Conrad C, Maru DM, Aloia TA, Vauthey JN: RAS Mutation Predicts Positive Resection Margins and Narrower Resection Margins in Patients Undergoing Resection of Colorectal Liver Metastases.Ann Surg Oncol 2016, 23:2635-2643.

9. Zimmitti G, Shindoh J, Mise Y, Kopetz S, Loyer EM, Andreou A, Cooper AB, Kaur H, Aloia TA, Maru DM, Vauthey JN: RAS mutations predict radiologic and pathologic response in patients treated with chemotherapy before resection of colorectal liver metastases.Ann Surg Oncol 2015, 22:834-842.

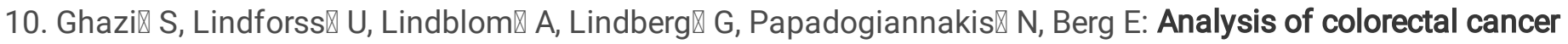
morphology in relation to sex, age, location, and family history.J Gastroenterol 2012, 47:619-634.

11. Yahagi M, Okabayashi K, Hasegawa H, Tsuruta M, Kitagawa Y: The Worse Prognosis of Right-Sided Compared with Left-Sided Colon Cancers: a Systematic Review and Meta-analysis.J Gastrointest Surg 2016, 20:648-655.

12. Birkenkamp-Demtroder K, Olesen SH, Sorensen FB, Laurberg S, Laiho P, Aaltonen LA, Orntoft TF: Differential gene expression in colon cancer of the caecum versus the sigmoid and rectosigmoid.Gut 2005, 54:374-384.

13. Azzoni C, Bottarelli L, Campanini N, Di Cola G, Bader G, Mazzeo A, Salvemini C, Morari S, Di Mauro D, Donadei E, et al: Distinct molecular patterns based on proximal and distal sporadic colorectal cancer: arguments for different mechanisms in the tumorigenesis.Int J Colorectal Dis 2007, 22:115-126.

14. Vigano L, Russolillo N, Ferrero A, De Rosa G, Ferreri E, Forchino F, Sperti E, Capussotti L: Resection of liver metastases from colorectal mucinous adenocarcinoma: is this a different disease? Results of a case-control study.Ann Surg 2014, 260:878-884; discussion 884-875.

15. Liu W, Wang HW, Wang K, Xing BC: The primary tumor location impacts survival outcome of colorectal liver metastases after hepatic resection: A systematic review and meta-analysis.Eur $J$ Surg Oncol 2019, Epub ahead of 
print.

16. Yu J, Wu WK, Li X, He J, Li XX, Ng SS, Yu C, Gao Z, Yang J, Li M, et al: Novel recurrently mutated genes and a prognostic mutation signature in colorectal cancer.Gut 2015, 64:636-645.

17. Loupakis F, Yang D, Yau L, Feng S, Cremolini C, Zhang W, Maus MK, Antoniotti C, Langer C, Scherer SJ, et al: Primary tumor location as a prognostic factor in metastatic colorectal cancer.J Natl Cancer Inst 2015, 107:dju427.

18. Meguid RA, Slidell MB, Wolfgang CL, Chang DC, Ahuja N: Is there a difference in survival between right- versus left-sided colon cancers? Ann Surg Oncol 2008, 15:2388-2394.

19. Yamauchi M, Morikawa T, Kuchiba A, Imamura Y, Qian ZR, Nishihara R, Liao X, Waldron L, Hoshida Y, Huttenhower $\mathrm{C}$, et al: Assessment of colorectal cancer molecular features along bowel subsites challenges the conception of distinct dichotomy of proximal versus distal colorectum.Gut 2012, 61:847-854.

20. Arnold D, Lueza B, Douillard JY, Peeters M, Lenz HJ, Venook A, Heinemann V, Van Cutsem E, Pignon JP, Tabernero $\mathrm{J}$, et al: Prognostic and predictive value of primary tumour side in patients with RAS wild-type metastatic colorectal cancer treated with chemotherapy and EGFR directed antibodies in six randomized trials.Ann Oncol 2017, 28:1713-1729.

21. Tejpar S, Stintzing S, Ciardiello F, Tabernero J, Van Cutsem E, Beier F, Esser R, Lenz HJ, Heinemann V: Prognostic and Predictive Relevance of Primary Tumor Location in Patients With RAS Wild-Type Metastatic Colorectal Cancer: Retrospective Analyses of the CRYSTAL and FIRE-3 Trials.JAMA Oncol 2017, 3:194-201.

22. Sasaki K, Andreatos N, Margonis GA, He J, Weiss M, Johnston F, Wolfgang C, Antoniou E, Pikoulis E, Pawlik TM: The prognostic implications of primary colorectal tumor location on recurrence and overall survival in patients undergoing resection for colorectal liver metastasis.J Surg Oncol 2016, 114:803-809.

23. Assumpcao L, Choti MA, Gleisner AL, Schulick RD, Swartz M, Herman J, Gearhart SL, Pawlik TM: Patterns of recurrence following liver resection for colorectal metastases: effect of primary rectal tumor site.Arch Surg 2008, 143:743-749.

24. Price TJ, Beeke C, Ullah S, Padbury R, Maddern G, Roder D, Townsend AR, Moore J, Roy A, Tomita Y, Karapetis C: Does the primary site of colorectal cancer impact outcomes for patients with metastatic disease? Cancer 2015, 121:830-835.

25. Wang K, Xu D, Yan XL, Poston G, Xing BC: The impact of primary tumour location in patients undergoing hepatic resection for colorectal liver metastasis. Eur J Surg Oncol 2018, 44:771-777.

26. Fubo Zhou, Xiaoling Yu, Ping Liang, Zhiyu Han, Zhigang Cheng, Jie Yu, Fangyi Liu, Hu Y: Does primary tumor location impact the prognosis of colorectal liver metastases patients after microwave ablation? - Lessons from 10 years' experience. Oncotarget 2017, 8:100791-100800.

27. Agcaoglu O, Aliyev S, Karabulut K, El-Gazzaz G, Aucejo F, Pelley R, Siperstein AE, Berber E: Complementary use of resection and radiofrequency ablation for the treatment of colorectal liver metastases: an analysis of 395 patients. World J Surg 2013, 37:1333-1339.

28. Lonjon G, Boutron I, Trinquart L, Ahmad N, Aim F, Nizard R, Ravaud P: Comparison of treatment effect estimates from prospective nonrandomized studies with propensity score analysis and randomized controlled trials of surgical procedures.Ann Surg 2014, 259:18-25.

29. Missiaglia E, Jacobs B, D'Ario G, Di Narzo AF, Soneson C, Budinska E, Popovici V, Vecchione L, Gerster S, Yan P, et al: Distal and proximal colon cancers differ in terms of molecular, pathological, and clinical features.Ann Oncol 2014, 25:1995-2001. 
30. Tran B, Kopetz S, Tie J, Gibbs P, Jiang ZQ, Lieu CH, Agarwal A, Maru DM, Sieber O, Desai J: Impact of BRAF mutation and microsatellite instability on the pattern of metastatic spread and prognosis in metastatic colorectal cancer.Cancer 2011, 117:4623-4632.

31. Knijn N, Mekenkamp LJ, Klomp M, Vink-Borger ME, Tol J, Teerenstra S, Meijer JW, Tebar M, Riemersma S, van Krieken JH, et al: KRAS mutation analysis: a comparison between primary tumours and matched liver metastases in 305 colorectal cancer patients.Br J Cancer 2011, 104:1020-1026.

32. Benedix F, Kube R, Meyer F, Schmidt U, Gastinger I, Lippert H, Colon/Rectum Carcinomas Study G: Comparison of 17,641 patients with right- and left-sided colon cancer: differences in epidemiology, perioperative course, histology, and survival.Dis Colon Rectum 2010, 53:57-64.

33. Holch JW, Ricard I, Stintzing S, Modest DP, Heinemann V: The relevance of primary tumour location in patients with metastatic colorectal cancer: A meta-analysis of first-line clinical trials. European Journal of Cancer2017, 70:87-98.

\section{Tables}

seline clinicopathological characteristics 


\begin{tabular}{|c|c|c|c|c|c|c|c|c|}
\hline \multirow[t]{2}{*}{ stics } & \multicolumn{4}{|c|}{ Before PSM (n=611) } & \multicolumn{4}{|c|}{ After PSM $(n=254)$} \\
\hline & $\begin{array}{l}\text { Right-sided } \\
\text { group } \\
(\mathrm{n}=141)\end{array}$ & $\begin{array}{l}\text { Left- } \\
\text { sided group } \\
(n=470)\end{array}$ & $\begin{array}{l}P- \\
\text { value }\end{array}$ & SMD & $\begin{array}{l}\text { Right-sided } \\
\text { group } \\
(\mathrm{n}=127)\end{array}$ & $\begin{array}{l}\text { Left- } \\
\text { sided group } \\
(\mathrm{n}=127)\end{array}$ & $\begin{array}{l}P \text { - } \\
\text { value }\end{array}$ & SMD \\
\hline \multirow{4}{*}{$\begin{array}{l} \pm \text { SD), years } \\
\%)\end{array}$} & $57( \pm 12)$ & $55( \pm 11)$ & \multirow{4}{*}{$\begin{array}{l}0.313 \\
0.538\end{array}$} & \multirow{4}{*}{$\begin{array}{l}-0.099 \\
0.065\end{array}$} & $56( \pm 12)$ & $54( \pm 12)$ & \multirow{4}{*}{$\begin{array}{l}0.381 \\
0.894\end{array}$} & \multirow{4}{*}{$\begin{array}{l}0.086 \\
0.016\end{array}$} \\
\hline & & & & & & & & \\
\hline & $92(65.2)$ & 321 (68.3) & & & $84(66.1)$ & $86(67.7)$ & & \\
\hline & $49(34.8)$ & 149 (31.7) & & & $43(33.9)$ & $41(32.3)$ & & \\
\hline \multirow{3}{*}{$\begin{array}{l}\text { mor characteristics } \\
\text { apy prior to CRC }\end{array}$} & & & \multicolumn{2}{|l|}{0.218} & & & \multirow{3}{*}{0.364} & \\
\hline & $37(26.4)$ & $156(33.3)$ & & & $35(27.8)$ & $43(33.9)$ & & \\
\hline & $103(73.6)$ & $313(66.7)$ & & & $91(72.2)$ & $84(66.1)$ & & \\
\hline \multirow[t]{3}{*}{ CRC and CRLM, n (\%) } & & & \multirow[t]{3}{*}{0.067} & & & & \multirow[t]{3}{*}{0.900} & \\
\hline & $69(48.9)$ & $271(57.7)$ & & & $62(48.8)$ & $64(50.4)$ & & \\
\hline & $72(51.1)$ & $199(42.3)$ & & & $65(51.2)$ & $63(49.6)$ & & \\
\hline \multirow[t]{4}{*}{$\begin{array}{l}\text { mean }( \pm \mathrm{SD}), \mathrm{cm} \\
\%)\end{array}$} & $4.2( \pm 2.3)$ & $3.6( \pm 2.2)$ & \multirow[t]{4}{*}{$\begin{array}{l}0.011^{*} \\
0.524\end{array}$} & & $4.2( \pm 2.3)$ & $3.7( \pm 2.4)$ & \multirow[t]{4}{*}{$\begin{array}{l}0.048^{*} \\
0.841\end{array}$} & \\
\hline & $9(6.4)$ & $40(8.5)$ & & & $8(6.3)$ & $10(7.9)$ & & \\
\hline & $118(83.7)$ & $433(83.8)$ & & & $114(89.8)$ & $112(88.9)$ & & \\
\hline & $14(9.9)$ & $36(7.7)$ & & & $5(3.9)$ & $5(3.9)$ & & \\
\hline \multirow[t]{3}{*}{ (\%) } & & & \multirow[t]{3}{*}{0.546} & -0.061 & & & 0.363 & -0.058 \\
\hline & $52(39.7)$ & $188(43.0)$ & & & $51(40.2)$ & $43(33.9)$ & & \\
\hline & $79(60.3)$ & $249(57.0)$ & & & $76(59.8)$ & $84(66.1)$ & & \\
\hline , n (\%) & & & 0.441 & & & & 0.348 & \\
\hline & $2(1.4)$ & $10(2.1)$ & & & $2(1.6)$ & $0(0.0)$ & & \\
\hline & $7(5.0)$ & $43(9.1)$ & & & $7(5.5)$ & $9(7.1)$ & & \\
\hline & 21 (14.9) & 73 (15.5) & & & $21(16.5)$ & $20(15.7)$ & & \\
\hline & $106(75.2)$ & $331(70.4)$ & & & $96(75.6)$ & $98(77.2)$ & & \\
\hline & $5(3.5)$ & $13(2.8)$ & & & $1(0.7)$ & $0(0.0)$ & & \\
\hline ve chemotherapy, n & & & 0.256 & & & & 0.475 & \\
\hline & $103(73.0)$ & 366 (77.9) & & & $91(71.7)$ & $97(76.4)$ & & \\
\hline & $38(27.0)$ & $104(22.1)$ & & & $36(28.3)$ & $30(23.6)$ & & \\
\hline 'acteristics & & & & & & & & \\
\hline n of CRLM, n (\%) & & & 0.253 & -0.113 & & & 0.883 & -0.062 \\
\hline lous & $35(24.8)$ & $140(29.8)$ & & & $31(24.4)$ & $29(22.8)$ & & \\
\hline & $106(75.2)$ & $330(70.2)$ & & & $96(75.6)$ & $98(77.2)$ & & \\
\hline те chemotherapy, n (\%) & & 207 (61 1) & $0.008 *$ & 0.268 & $61(50-1)$ & $62(100)$ & 0.900 & -0.045 \\
\hline & $\begin{array}{l}08(48.2) \\
73(51.8)\end{array}$ & $183(38.9)$ & & & $\begin{array}{l}04(30.4) \\
63(49.6)\end{array}$ & $65(51.2)$ & & \\
\hline $\begin{array}{l}\text { re CEA }(\mu g / L),(>200 / \\
\text { \%)] }\end{array}$ & $\begin{array}{l}6 / 135 \\
(4.3 / 95.7)\end{array}$ & $\begin{array}{l}23 / 447 \\
(4.9 / 95.1)\end{array}$ & 0.755 & -0.008 & $\begin{array}{l}6 / 121 \\
(4.7 / 95.3)\end{array}$ & $\begin{array}{l}5 / 122 \\
(3.9 / 96.1)\end{array}$ & 1.000 & -0.042 \\
\hline $\begin{array}{l}\text { те CA19-9 (kU/L), , } \\
\text { [n (\%)] }\end{array}$ & $\begin{array}{l}30 / 110 \\
(21.4 / 78.6)\end{array}$ & $\begin{array}{l}97 / 370 \\
(20.8 / 79.2)\end{array}$ & 0.867 & & $\begin{array}{l}26 / 100 \\
(20.6 / 79.4)\end{array}$ & $\begin{array}{l}24 / 103 \\
(18.9 / 81.1)\end{array}$ & 0.754 & \\
\hline$(\mathrm{cm})$, median $(\mathrm{IQR})$ & $3.0(2.0-4.5)$ & $\begin{array}{l}2.8(1.6- \\
4.0)\end{array}$ & 0.095 & -0.164 & $3.0(1.8-4.0)$ & $\begin{array}{l}3.0 \quad(1.5- \\
4.0)\end{array}$ & 0.944 & -0.013 \\
\hline$(\%)$ & & & 1.000 & & & & 0.196 & \\
\hline & $79(56.4)$ & $263(56.6)$ & & & $72(57.1)$ & $81(65.3)$ & & \\
\hline & $61(43.6)$ & $202(43.4)$ & & & $54(42.9)$ & $43(34.7)$ & & \\
\hline tumors, n (\%) & $79(56.0)$ & $275(58.5)$ & 0.627 & 0.082 & $73(575)$ & $67(528)$ & 0.528 & -0.015 \\
\hline & $62(44.0)$ & $195(41.5)$ & & & $54(42.5)$ & $60(47.2)$ & & \\
\hline $\mathrm{n}, \mathrm{n}(\%)$ & & & 1.000 & & & & 0.886 & \\
\hline & $119(84.4)$ & $396(84.4)$ & & & $106(83.5)$ & $106(84.1)$ & & \\
\hline & $22(15.6)$ & $73(15.6)$ & & & $21(16.5)$ & $20(15.9)$ & & \\
\hline tive chemotherapy, $\mathrm{n}$ & & & 0.455 & & & & 1.000 & \\
\hline & $98(69.5)$ & $342(72.8)$ & & & $89(70.1)$ & $90(70.9)$ & & \\
\hline & $43(30.5)$ & $128(27.2)$ & & & $38(29.9)$ & $37(29.1)$ & & \\
\hline n (\%) & & & 0.538 & & & & 0.922 & \\
\hline & $90(64.7)$ & 312 (67.7) & & & $88(71.0)$ & $88(70.4)$ & & \\
\hline & $49(35.3)$ & 149 (32.3) & & & $36(29.0)$ & $37(29.6)$ & & \\
\hline
\end{tabular}

ısity score matching; SD, standard deviation; IQR, inter-quartile range; $\mathrm{T}$ stage, tumor stage; $\mathrm{N}$ stage, node stage; CRLM, C। IEA, carcinoembryonic antigen; CA 19-9, carbohydrate antigen 19-9; R0 resection, hepatectomy on patients with clear histological r. mean differences; $* P<0.05$.

gnostic factors for overall survival and recurrence-free survival 


\begin{tabular}{|c|c|c|c|c|c|c|c|c|}
\hline \multirow[t]{3}{*}{ stics } & \multicolumn{4}{|c|}{ Overall survival } & \multicolumn{4}{|c|}{ Recurrence-free survival } \\
\hline & \multirow{2}{*}{$\begin{array}{c}\text { Univariate } \\
P \text {-value } \\
\end{array}$} & \multicolumn{3}{|c|}{ Multivariate analysis } & \multirow{2}{*}{$\begin{array}{c}\text { Univariate } \\
P \text {-value } \\
\end{array}$} & \multicolumn{3}{|c|}{ Multivariate analysis } \\
\hline & & HR & $95 \% \mathrm{CI}$ & $P$-value & & HR & $95 \% \mathrm{CI}$ & $P$-value \\
\hline$(\leq 55$ vs. $>55)$ & 0.477 & & & & 0.786 & & & \\
\hline $\begin{array}{l}\text { ale vs. female) } \\
\text { ition }\end{array}$ & 0.785 & & & & 0.479 & & & \\
\hline $\begin{array}{l}\text { d vs. right-sided } \\
\text { mor characteristics }\end{array}$ & 0.575 & & & & $0.029 *$ & 0.659 & $0.478-0.910$ & $0.011 *$ \\
\hline 3/T4 vs. T1/T2) & 0.201 & & & & 0.219 & & & \\
\hline $\begin{array}{l}1 / \mathrm{N} 2 \text { vs. N0) } \\
(\mathrm{cm}),(>4 \text { vs. } \leq 4)\end{array}$ & $\begin{array}{l}0.001^{*} \\
0.254\end{array}$ & 1.600 & $1.155-2.216$ & $0.005 *$ & $\begin{array}{l}0.003 * \\
0.628\end{array}$ & 1.533 & $1.159-2.029$ & $0.003 *$ \\
\hline $\begin{array}{l}\text { ive chemotherapy } \\
\text { ) } \\
\text { racteristics }\end{array}$ & 0.501 & & & & $0.018^{*}$ & 1.417 & $0.944-2.217$ & 0.093 \\
\hline $\begin{array}{l}\text { on of CRLM } \\
\text { jus vs. asynchronous) }\end{array}$ & 0.766 & & & & 0.190 & & & \\
\hline ve chemotherapy & [0.001* & 1.279 & $0.898-1.822$ & 0.172 & $0.001 *$ & 1.355 & $0.975-1.884$ & 0.070 \\
\hline$),(>200$ vs. $\leq 200)$ & $0.020 *$ & 1.166 & $0.560-2.428$ & 0.681 & 0.056 & & & \\
\hline $\mathrm{J} / \mathrm{L}),(>35$ vs. $\leq 35)$ & $0.015 *$ & 1.285 & $0.854-1.933$ & 0.229 & 0.748 & & & \\
\hline$(\mathrm{cm}),(>5$ vs. $\leq 5)$ & $0.001 *$ & 1.923 & $1.298-2.849$ & $0.001 *$ & 0.315 & & & \\
\hline aber (multiple vs. single) & $\square 0.001 *$ & 1.446 & $0.988-2.117$ & 0.058 & $\square 0.001 *$ & 1.244 & $0.907-1.706$ & 0.176 \\
\hline $\begin{array}{l}\text { factors } \\
\text { ion vs. resection only) }\end{array}$ & $\square 0.001 *$ & 1.723 & $1.129-2.630$ & 0.012 & $\square 0.001 *$ & 1.793 & $1.253-2.566$ & $0.001 *$ \\
\hline Jn (no vs. yes) & $\square 0.001 *$ & 1.998 & $1.424-2.804$ & $\square 0.001 *$ & & & & \\
\hline ive chemotherapy & 0.057 & & & & 0.319 & & & \\
\hline
\end{tabular}

ratio; CI, confidence interval; $\mathrm{T}$ stage, tumor stage; $\mathrm{N}$ stage, node stage; CRLM, colorectal liver metastases; CEA, carcinoembryonic a rate antigen 19-9; R0 resection, hepatectomy on patients with clear histological margins; ${ }^{*} \mathrm{P}<0.05$.

Table 3 Treatment of recurrence for patients after liver metastases resection

\begin{tabular}{|c|c|c|c|c|c|c|}
\hline \multirow[t]{2}{*}{ Characteristics } & \multicolumn{3}{|c|}{ Before PSM $(n=240)$} & \multicolumn{3}{|c|}{ After PSM $(n=99)$} \\
\hline & $\begin{array}{l}\text { Right-sided } \\
\text { group } \\
(\mathrm{n}=54)\end{array}$ & $\begin{array}{l}\text { Left- } \\
\text { sided group } \\
(\mathrm{n}=186)\end{array}$ & $\begin{array}{l}P \text { - } \\
\text { value }\end{array}$ & $\begin{array}{l}\text { Right-sided } \\
\text { group } \\
(n=53)\end{array}$ & $\begin{array}{l}\text { Left- } \\
\text { sided group } \\
(\mathrm{n}=46)\end{array}$ & $P$-value \\
\hline Resection alone, n (\%) & $3(5.6)$ & $20(10.7)$ & 0.306 & $3(5.7)$ & $9(19.6)$ & 0.134 \\
\hline Ablation alone, $\mathrm{n}(\%)$ & $11(20.4)$ & $29(15.6)$ & 0.407 & $11(20.8)$ & $7(15.2)$ & 0.476 \\
\hline Chemotherapy alone, n (\%) & $27(50.0)$ & 70 (37.7) & 0.103 & $18(34.0)$ & $17(37.0)$ & 0.756 \\
\hline $\begin{array}{l}\text { Resection + chemotherapy, } \mathrm{n} \\
(\%)\end{array}$ & $3(5.6)$ & $9(4.8)$ & 0.735 & $3(5.7)$ & $2(4.3)$ & 1.000 \\
\hline Resection + radiotherapy, n (\%) & $1(1.8)$ & $3(1.6)$ & 0.905 & $1(1.8)$ & $0(0.0)$ & NA \\
\hline Ablation + chemotherapy, n (\%) & $3(5.6)$ & $25(13.4)$ & 0.149 & $3(5.7)$ & $2(4.3)$ & 1.000 \\
\hline Ablation + radiotherapy, n (\%) & $0(0.0)$ & $2(1.1)$ & NA & $0(0.0)$ & $0(0.0)$ & NA \\
\hline Radio + chemotherapy, n (\%) & $0(0.0)$ & $2(1.1)$ & NA & $0(0.0)$ & $0(0.0)$ & $\mathrm{NA}$ \\
\hline Supportive care, n (\%) & $6(11.1)$ & $26(14.0)$ & 0.585 & $14(26.4)$ & $9(19.6)$ & 0.421 \\
\hline
\end{tabular}

PSM, propensity score matching; 
a

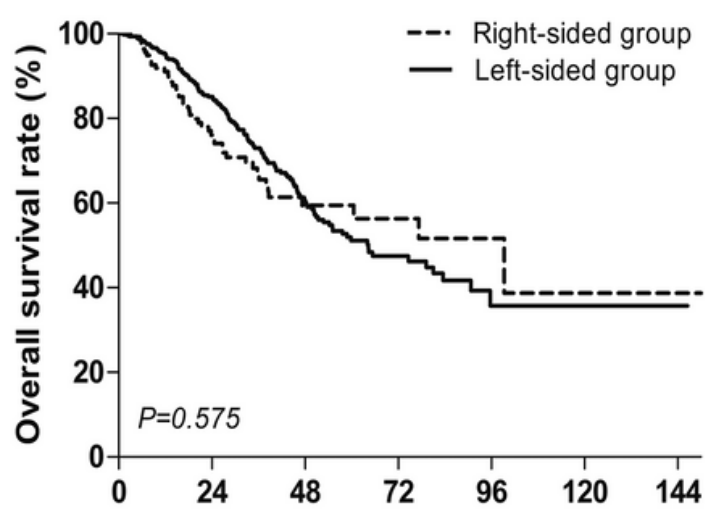

Number at risk

Time after liver metastases resection (months)

$\begin{array}{llllllll}\text { Right-sided group } 141 & 77 & 30 & 13 & 9 & 2 & 1\end{array}$

Left-sided group $\begin{array}{lllllll}470 & 275 & 108 & 40 & 4 & 1 & 1\end{array}$

C

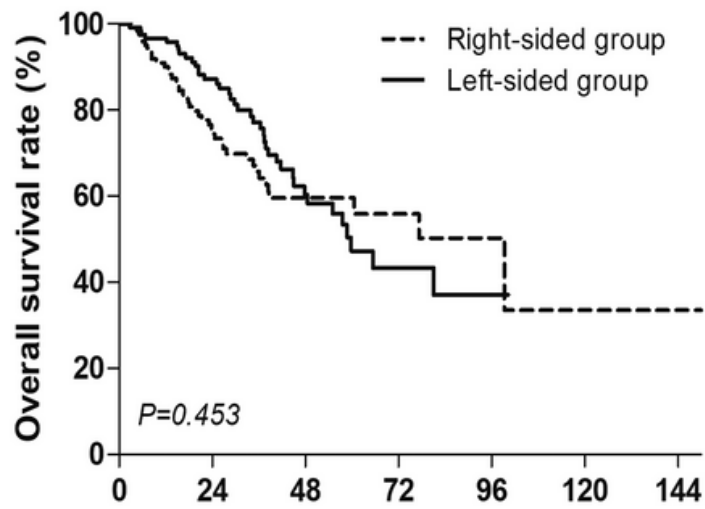

Number at risk

Time after liver metastases resection (months) b

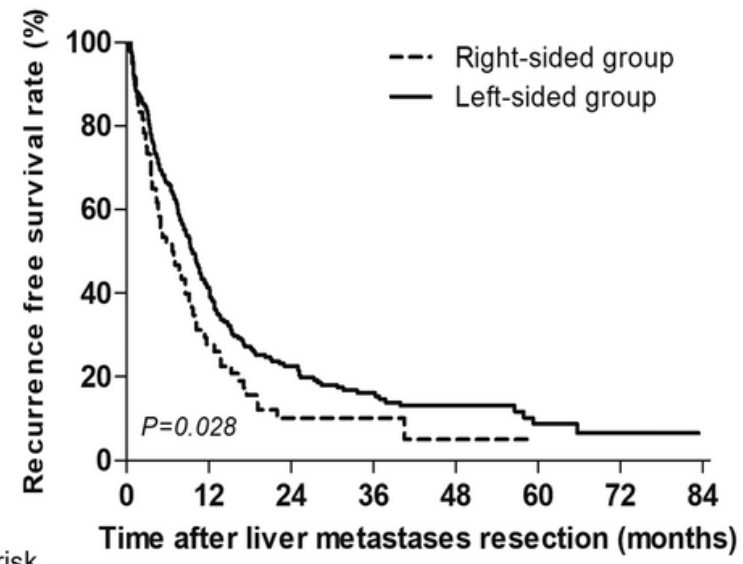

Number at risk

$\begin{array}{lrccccccc}\text { Right-sided group } & 61 & 16 & 5 & 2 & 1 & 6 & 2 & 1\end{array}$

$\begin{array}{llllllll}\text { Left-sided group } 225 & 86 & 42 & 23 & 13 & 0 & 0 & 0\end{array}$

d

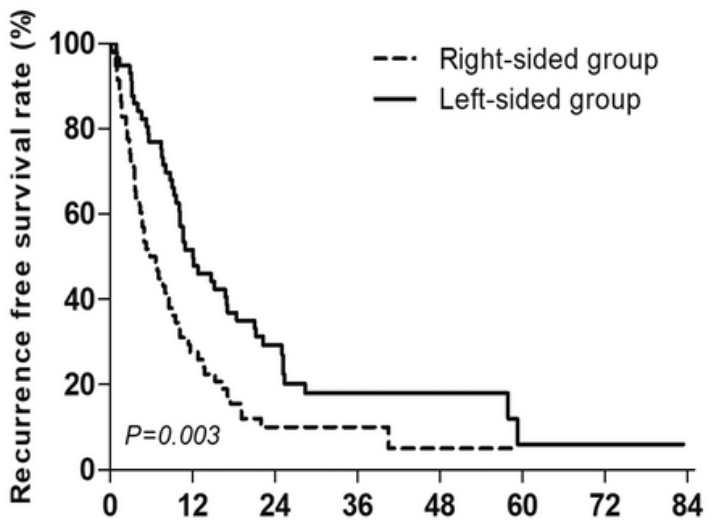

Number at risk

Time after liver metastases resection (months)

$\begin{array}{llllllll}\text { Right-sided group } 59 & 16 & 5 & 2 & 1 & 1 & 1 & 1 \\ \text { Left-sided group } 59 & 28 & 13 & 7 & 5 & 0 & 0 & 0\end{array}$

\section{Figure 1}

(a) Overall survival (b) recurrence free survival in CRLM patients stratified by CRC location. (c) Overall survival and (d) recurrence free survival in CRLM patients stratified by CRC location after PSM. 
a

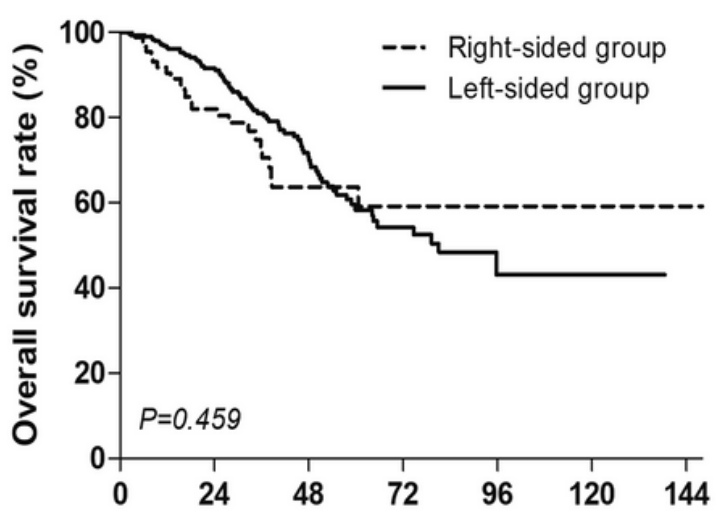

Number at risk

$\begin{array}{llllllll}\text { Right-sided group } & 90 & 55 & 22 & 10 & 4 & 2 & 2\end{array}$

$\begin{array}{llllllll}\text { Left-sided group } & 312 & 200 & 86 & 33 & 8 & 2 & 1\end{array}$

C

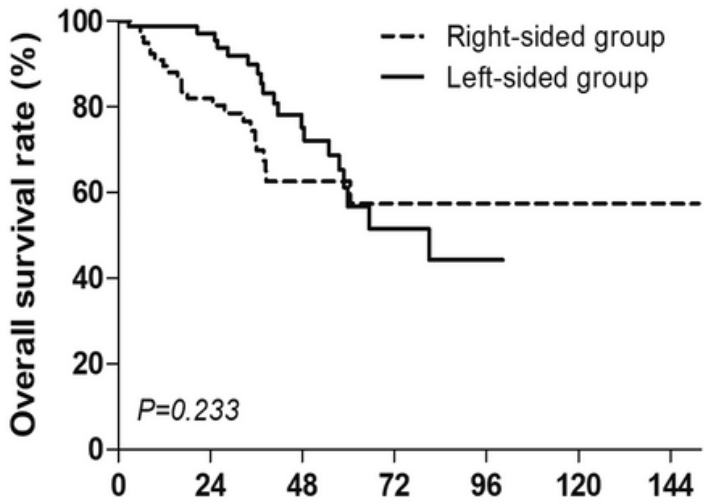

Number at risk

Time after liver metastases resection (months)

Right-sided group

Left-sided group b

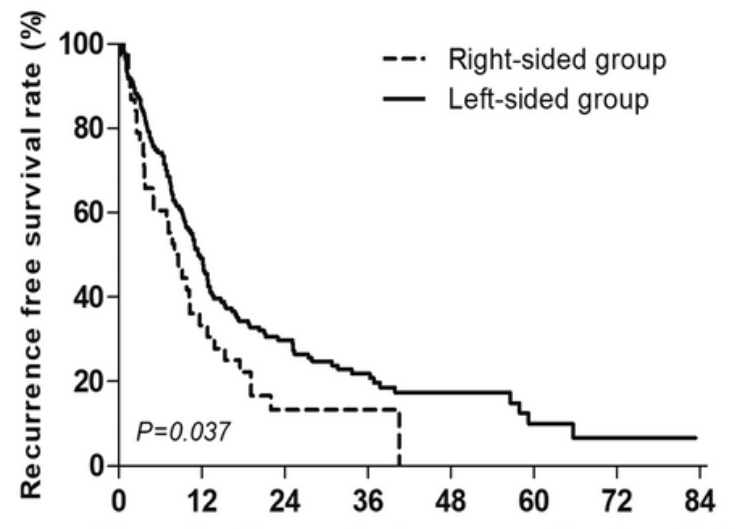

Number at risk

Time after liver metastases resection (months)

$\begin{array}{lllclllll}\text { Right-sided group } & 38 & 13 & 5 & 2 & 1 & 1 & 1 & 1\end{array}$
$\begin{array}{llllllll}\text { Left-sided group } 145 & 68 & 39 & 22 & 12 & 5 & 2 & 1\end{array}$

d

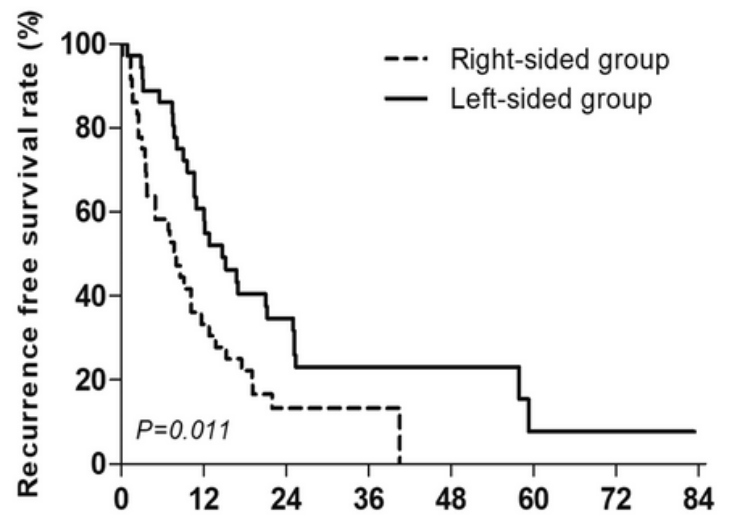

Number at risk

Time after liver metastases resection (months)

$\begin{array}{llllllll}\text { Right-sided group } 36 & 12 & 4 & 1 & 0 & 0 & 0 & 0 \\ \text { Left-sided group } 36 & 21 & 12 & 7 & 5 & 1 & 1 & 1\end{array}$

\section{Figure 2}

(a) Overall survival and (b) recurrence free survival in CRLM patients stratified by CRC location with low CRS scores (score $\leq 2$ ). (c) Overall survival and (d) recurrence free survival in CRLM patients stratified by CRC location with low CRS scores after PSM. 
a

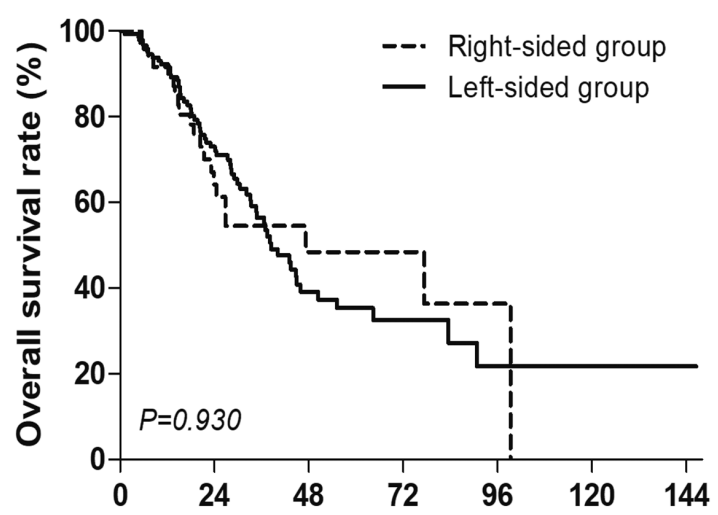

Number at risk

Time after liver metastases resection (months)

$\begin{array}{llllllll}\text { Right-sided group } & 49 & 23 & 9 & 5 & 2 & 1 & 1\end{array}$

b

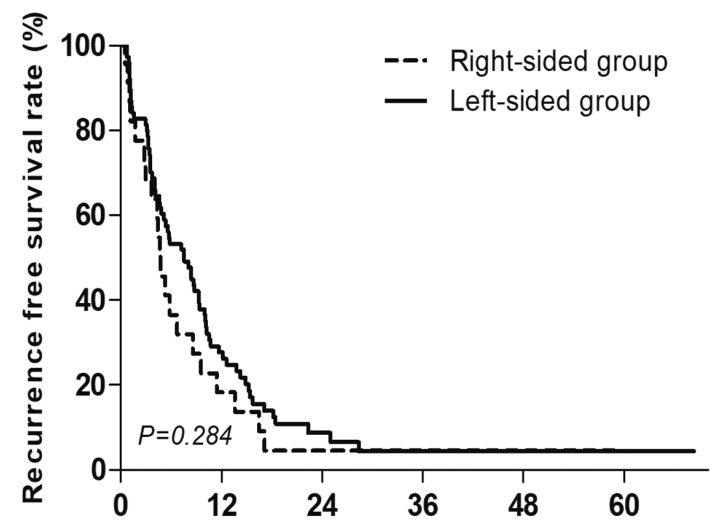

Time after liver metastases resection (months)

Number at risk

$\begin{array}{llcllll}\text { Right-sided group } & 23 & 5 & 2 & 2 & 2 & 1 \\ \text { Left-sided group } & 77 & 20 & 5 & 3 & 3 & 2\end{array}$

Left-sided group
C

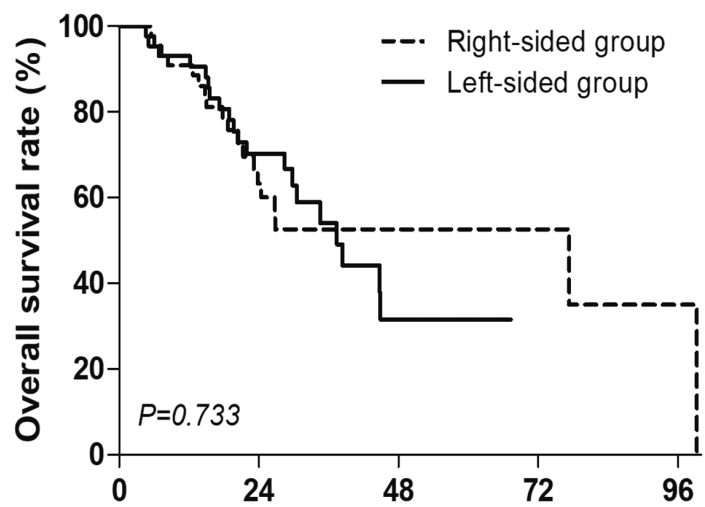

Number at risk

Time after liver metastases resection (months)

7
5

3
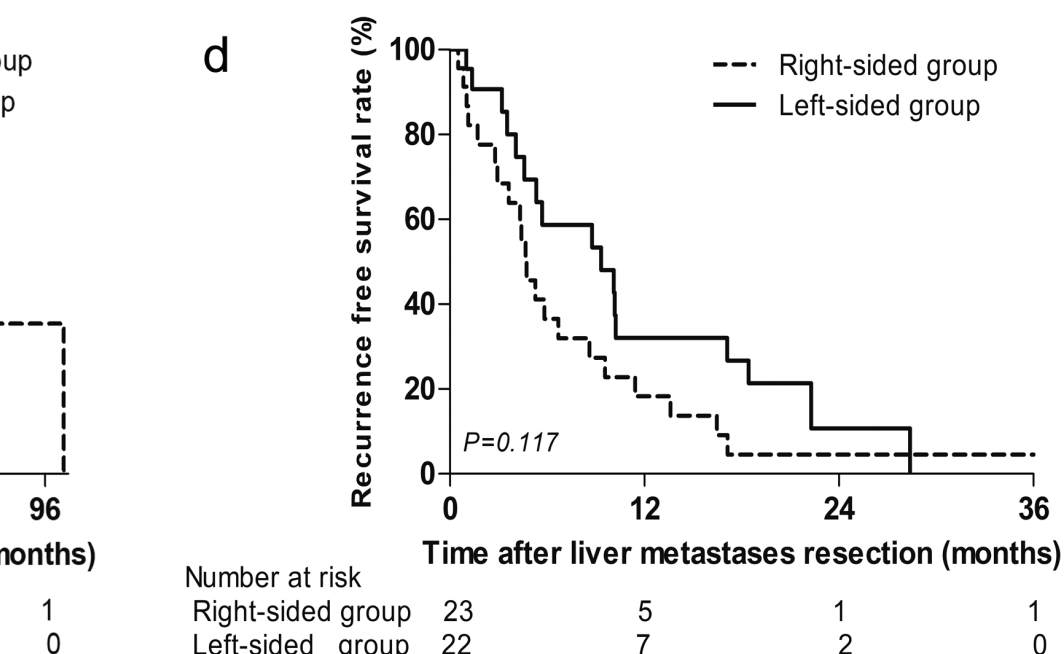

Number at risk

Time after liver metastases resection (months)

Right-sided group 23

Left-sided group 22

$\begin{array}{ll}5 & 1 \\ 7 & 2\end{array}$

\section{Figure 3}

(a) Overall survival and (b) recurrence free survival in CRLM patients stratified by CRC location with high CRS scores (score $\varangle 2$ ). (c) Overall survival and (d) recurrence free survival in CRLM patients stratified by CRC location with high CRS scores after PSM.

\section{Supplementary Files}

This is a list of supplementary files associated with this preprint. Click to download.

- SupplementaryFigure1.tif

- SupplementaryFigure2.tif

- supplementary.pdf 